高分子物質を含むリファンピシンゲル軟專からの

リファンピシンの放出特性*1

安生紗枝子, 松尾直枝, 近藤由利子*2, 野呂俊一*3

東邦大学医学部附属大森病院薬剂部*2

明治薬科大学物理化学研究室*3

\title{
The Release of Rifampicin from Rifampicin Gel Containing Polymer*1
}

\author{
SAEKo ANJo, NAOE MATSUO, YURIKo KONDO*2, and ShUNICHI NORO*3 \\ Department of Pharmacy, Toho University Omori Hospital*2 \\ The Department of Physical Chemistry, Meiji Pharmaceutical College*3
}

(Received December 25, 1986)

\begin{abstract}
Rifampicin(RFP) gels were prepared by using polymer, surfactant and water, and their pharmaceutical characteristics were evaluated. Sodium polyacrylate (PAA-Na) and sodium carboxymethyl cellulose (CMC-Na) were used as polymers, and polysorbate 80 (Tween 80 ) and hydrogenated castor oil-polyoxyethylene castor oil (HCO-60) were used as surfactants. The release of RFP from the gel was measured through a cellulose membrane (Millipore Co.) using a dissolution test instrument (Toyama Sangyo Co.). Furthermore, the gel's characteristics in viscosity were evaluated with a viscometer.

The following results were obtained:

1. As the viscosity of the gel base is increased, the release of RFP from the gel base decreases. 2. The RFP release rate from gel base containing PAA-Na was higher than that containing CMC-Na. 3. No significant effect of surfactant concentration on the release of RFP from the gel base was found. 4. The pharmaceutical design of RFP gel including a polymer may be possible by further studies of stability, rheology and bioavailability.
\end{abstract}

Keywords_-rifampicin; hydrogel; polymer; polyacrylate; carboxymethylcellulose; surfactant; polysorbate 80 ; polyoxyethylene castor oil-hydrogenated castor oil; release rate; viscosity

リフォンピシン (RFP) は経ロ風として開発された が，1970年，結核性膿胸の注入液として用いられた ${ }^{1)}$ を始めとして，種々の剂形 2 4) の検討が行われるように なった，著者らは前報らで注入液として用いるために界 面活性斉で可溶化した RFP 液の安定性について報告し た.この RFP 液を結核性㢞孔の注入液として用いた結 果, 液状のため, 瘦孔からの漏出が認められた. そこ

*1 本報を「リファンピシンの整剤学的応用」第 2 報 とする．日本薬学会第102年会(神戸，1982年 4 月) で発表.

*2 東京都大田区大森 西 6 丁目 11-1；11-1, Omorinishi 6-chome, Ota-ku, Tokyo, 143 Japan

*3 東京都田無市谷戸町 1 丁目 22-1；22-1, Yato-cho 1-chome, Tanashi-shi, Tokyo, 188 Japan
でこれらの漏出を防ぐことを目的として増粘性のある 製剤の開発を試みた。

基剤からの薬物の放出特性や生体内への吸収性は主 薬, 基剤, 添加剂により大きく影響を受ける.そこで, 本研究では増粘効果が大きく, また, 薬物の分散に対し ても安定性作用を有している水溶性高分子物質を用い て，RFP ゲルを調製し，ゲル基剤から RFP の放出性に 対する水溶性高分子及び非イオン型界面活性剤の影響に ついて実験的考察を行い，若干の知見を得たので報告す る.

\section{実 験 の 部}

\section{1. 使用物買}

主薬には RFP (第一製薬) を用いた，高分子物質に 
はポリアクリル酸ナトリウム（以下 PAA-Na, 分子量 $6.6 \times 10^{6}$, 和光純薬) 及びカルボキシメチルセルロース (和光純薬 $\mathrm{K} . \mathrm{K}$ ) 及びカルボキシメチルセルロースナ トリウム（以下 $\mathrm{CMC}-\mathrm{Na}$, 分子量 $8.0 \times 10^{4}$, 和光純薬） を用いた. 界面活性剤にはポリオキシェチレンソルビタ ソモノオレェート(以下 Tween 80, 関東化学) 及びポ リオキシェチレンヒマシ油, 硬化ヒマシ油誘導体 (以下 $\mathrm{HCO}-60$, 日光ヶミカルズ社) を用いた.

\section{RFP ゲルの調製方法}

高分子物質を一定量の精製水中に加え，一尽夜膨潤さ せゲル基剤とした．高分子濃度は $0.3 〜 10 \%(\mathrm{w} / \mathrm{v})$ ，ま た界面活性剤濃度は0.3〜10\%(w/v) の水溶液とした。 この界面活性剂水溶液に主薬を加え，先に調製しておい たゲル基剤中に懸濁させ RFP ゲルを製した。なお，主 薬の濃度は $0.3 \%(\mathrm{w} / \mathrm{w})$ 一定とした. ゲル中に気泡が 存在する場合は隇圧により除去した。

\section{3. 放出試験}

坐剂放出試験器(富山産業)を用いた. 放出相は $0.05 \mathrm{M}$ リン酸緩衝液 $\left(\mathrm{pH} \mathrm{7.0)}\right.$ とし, 温度 $37^{\circ} \mathrm{C}+1$, 回転数 $100 \mathrm{rpm}$ で行った. 試料相には人工膜(Millipore SSWO 4700, Millipore Co.) を使用し, 試料 $2.5 \mathrm{~g}$ をのせ, 回 転速度 $25 \mathrm{rpm}$ で行った. 60分まで一定時間毎にサンプ リングし，サンプリング後は同量の試験液を補充した. 溶出した RFP の濃度は分光光度計（島津ダブルビーム 200S）により励起波長 $475 \mathrm{~nm}$ で測定した.

\section{4. 粘度測定}

単一円筒型回転粘度形ビスメトロン VS-A1 型（芝浦 システム製) 及びレオメーターシマズ RM-1 型（島津）
を使用した。

\section{結果及び考察}

RFP ゲルの粘度特性に対する高分子物質の種類と濃 度の影響をFig. 1 に示した. ずり速度の増加に伴い, 基 剤の粘度は減少し，ゲル基剤としてのレオロジー特性が みられた．また，高分子濃度を增加させることにより， ゲルの粘度は著しく増加し，ずり速度の增加に対する粘 度の減少率は PAA-Na の方が CMC-Na より大きかっ

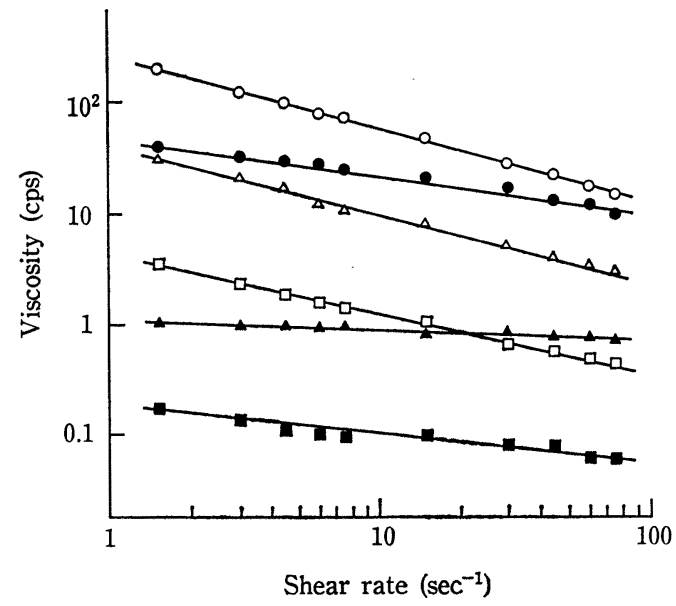

Fig. 1. Rheological Characteristics of RFP Gel Containing Various Polymers

; $0.1 \% \mathrm{CMC}-\mathrm{Na}, \boldsymbol{\Delta} ; 1 \% \mathrm{CMC}-\mathrm{Na}$, ; $3 \% \mathrm{CMC}-\mathrm{Na}, \square ; 0.1 \%$ PAA-Na, $\triangle ; 1 \%$ PAA-Na, $\bigcirc ; 3 \%$ PAA-Na

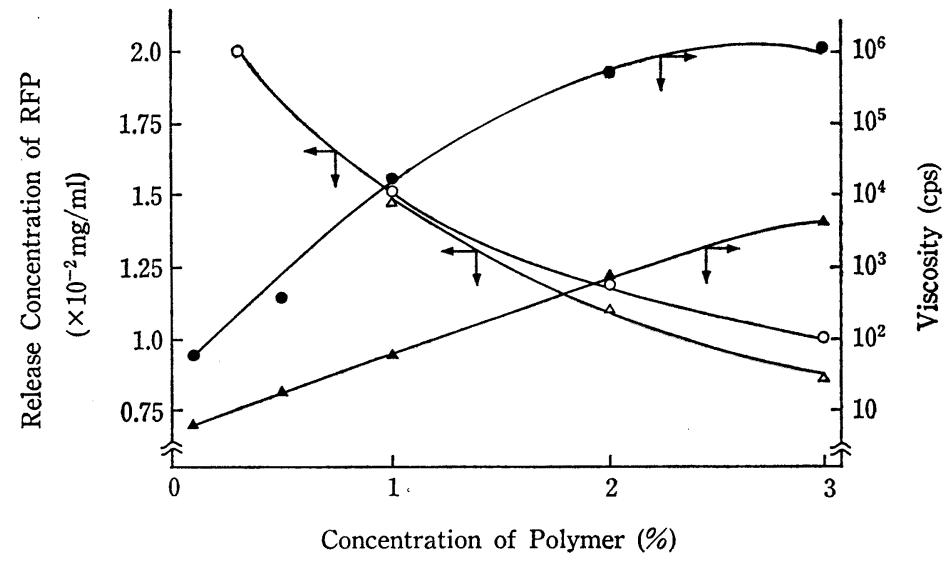

Fig. 2. Effect of the Concentration of Polymer on the Release of RFP and on the Viscosity of RFP Gel

$\mathrm{O}$; $\mathrm{PAA}-\mathrm{Na}, \triangle \boldsymbol{\Delta} ; \mathrm{CMC}-\mathrm{Na}$ 

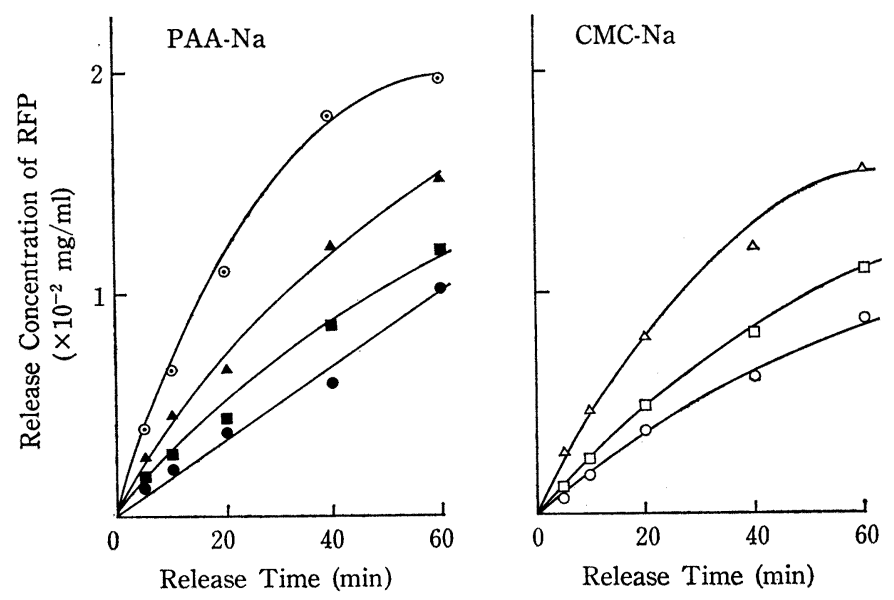

Fig. 3. Effect of Polymer on the Release of RFP from RFP Gel
( $; 0.3 \% \mathrm{PAA}-\mathrm{Na}, \triangle ; 1 \% \mathrm{PAA}-\mathrm{Na}$,
$; 2 \%$
PAA-Na, ; $3 \% \mathrm{PAA}-\mathrm{Na}, \triangle ; 1 \% \mathrm{CMC}-\mathrm{Na}$, $\square ; 2 \% \mathrm{CMC}-\mathrm{Na}, \mathrm{O} ; 3 \% \mathrm{CMC}-\mathrm{Na}$
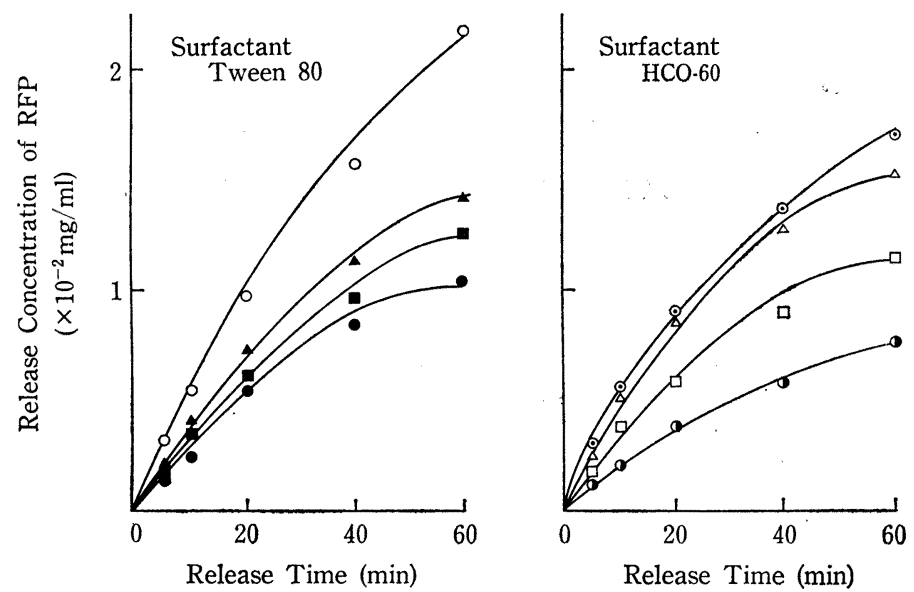

Polymer PAA-Na, 0.3\%

Fig. 4. Effect of Surfactant on the Release of RFP from Gel Containing 0.3\% PAA-Na $\bigcirc ; 0.3 \%$ Tween $80, \Delta ; 1 \%$ Tween $80, \square ; 3 \%$ Tween $80, \bigcirc 10 \%$ Tween 80 , $; 0.3 \%$ HCO-60, $\triangle ; 1 \% \mathrm{HCO}-60, \square ; 3 \% \mathrm{HCO}-60,0 ; 10 \% \mathrm{HCO}-60$

た。

RFP 放出量及びゲル基剤の粘度に対する高分子濃度 の影響はFig. 2 亿示すように, 高分子濃度の増加にとも ないダル基剤の粘度も增加したが，一方，薬物放出量は 減少した。この薬物の基剤からの放出速度が高粘度性の 基剤では低粘度性の基凨よりも遅い6,7) という現象は水 性ゲル基郕を用いた Brunner ら
示した.

ゲル基剤からの RFP の放出特性は Fig. 3 亿示すよう 飞, 高分子濃度が $1 \sim 3 \%$ 範囲では両基剤間では放出 時間に対し類似した薬物放出曲線を示し，両基剤間での in vitro に括斿る薬物放出特性はほぼ同等であることが 明らかになった。なお， CMC-Naを $0.3 \%$ 使用した場 合，ゲル基剤が低粘性すぎるため，放出実験の初期にお 
いて人工膜を通過し，測定不能であった．

RFP のゲル基剤からの放出特性に対する界面活性剂 の影響を Fig. 4 及び Fig. 5 に示した. RFP ゲルは界 面活性剤の種類に関係なくその濃度の増加に 伴い RFP の放出速度は減少したが， CMC-Na の方が濃度依存性 が少なかった。 また, 界面活性剤の添加濃度が0.3〜10\% の範囲では, とくに薬物放出効果は認められず, 無添加 と比較するとむしろ㧕制傾向が認められた. そこで, 薬 物放出速度と界面活性剂濃度の相関をみるために, さら
に0.3\% 以下について検討を加えた. その結果, Fig. 6 に示すように, 界面活性阂濃度が $0.01 \sim 0.1 \%$ の範囲に おいて RFP の放出量は最大值を示した。

以上の結果より, 界面活性剂濃度と RFP の溶解性に ついて考察する. 界面活性剂の基剤への添加濃度がミセ ル形成臨界濃度付近までは薬物粒子の分散性またはぬれ をよくする作用を有している．しかし，ミセル形成濃度 以上に界面活性剂が添加されると薬物が界面活性剤の数 十分子会合したミセル内に包合され安定化するため，む
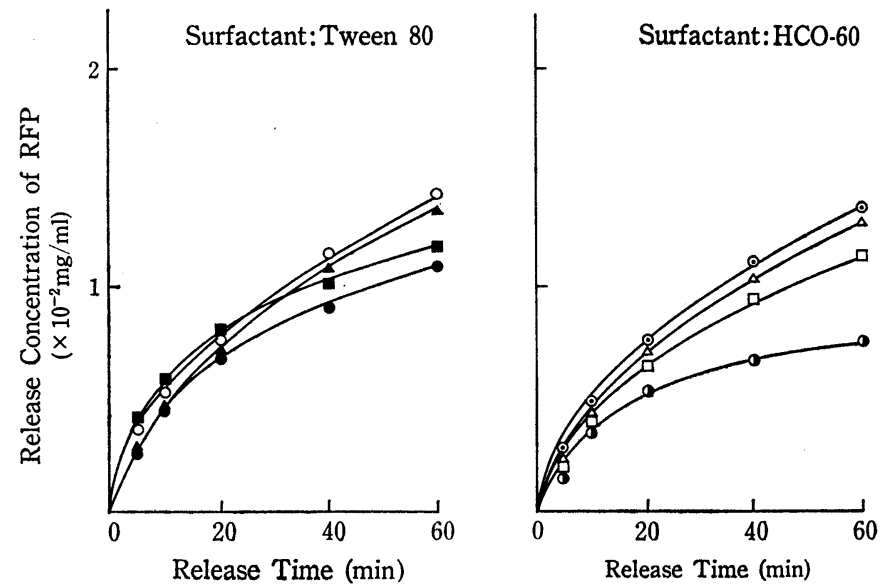

Polymer CMC-Na $1.0 \%$

Fig. 5. Effect of Surfactant on the Release of RFP from Gel Containing $1 \% \mathrm{CMC}-\mathrm{Na}$ $\bigcirc ; 0.3 \%$ Tween $80, \Delta ; 1 \%$ Tween $80, \square ; 3 \%$ Tween $80, \bigcirc ; 10 \%$ Tween $80, \bigcirc ; 0.3 \%$ HCO-60, $\triangle ; 1 \% \mathrm{HCO}-60, \square ; 3 \% \mathrm{HCO}-60,0 ; 10 \% \mathrm{HCO}-60$

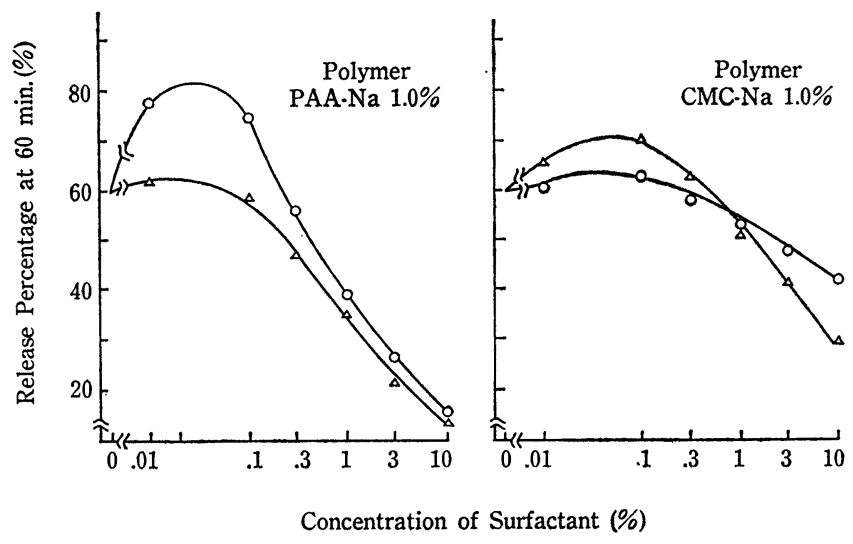

Fig. 6. Relation between the Release of RFP at 60 Minutes and Surfactant Concentration $\mathrm{O}$; Tween $80, \triangle$; HCO-60 
しろ, 基阂から放出されにくくなる8 ためであろらと考 えられる。

\section{結 諭}

RFP のゲル基剤からの放出性に及ぼす高分子物質及 び界面活性剂の影響を調べた結果，下記の結論が得られ た.

1. 高分子物質の濃度の增加にともない，ゲル基剤の 粘度は著しく増加した. 一方, 高粘度のゲル基剤ほど薬 物放出速度は減少した.

2. 高分子物質は PAA-Na の方が CMC-Na より高 い薬物放出を示した.

3. 前報ら)で記述したように，界面活性剤は固体薬物 粒子の溶解性を増大させているが, 界面活性剤添加によ る基剤からの薬物放出効果はとくに認められなかった。 界面活性剂の濃度が $0.1 \sim 0.01 \%$ の範囲内で RFP 放出 速度は最大值を示した.

4. 今後, さらに製刘の安定性, レオロジー特性及び in vivo のバイオアベイラビリティーなどを検討するこ
とにより，RFP ゲルの製剤設計が可能になるると考兄 られる。

\section{引用 文 献}

1. P. Czanic, L. Levendel: Prax. Pneumol, 24 (12), 764 (1970).

2. 古賀良平, 吉村輝仁永, 渡辺 康, 永井忠之：日 胸, 34 (5), 369 (1975).

3. 前川喜平, 小野友道, 藤原邦彦: 西日本皮虐, 35 (2), 153 (1973).

4. 植田君年, 吉田弘道: 医薬ジャ一ナル, 17 (4), 47 (1981).

5. 安生紗枝子, 松尾直枝, 近藤由利子, 野呂俊一： 病院薬学, 13(5), 288 (1987).

6. B.H.S.Brunner \& P.P.Speiser: J. Pharm., 28, 23 (1976).

7. R.D. Schoenwald, R. L. Wald, L. M. Desantis and R.E. Roehrs: J. Pharm. Sci., 67(9), 1280 (1978).

8. G. Levy, et al.: J. Pharm. Sci., 55, 394 (1966) 